\title{
EVALUATION OF GROUND INFORMATION WITH RESPECT TO EPB TUNNELLING FOR THE THESSALONIKI METRO, GREECE
}

\author{
Marinos P.G. ${ }^{1}$, Novack M. ${ }^{2}$, Benissi M. ${ }^{2}$, Stoumpos G. ${ }^{3}$, Panteliadou M. ${ }^{4}$, \\ Papouli D. ${ }^{4}$, Marinos V. ${ }^{1}$, and Korkaris K. ${ }^{2}$
}

\author{
${ }^{1}$ National Technical University of Athens, Faculty of Civil Engineering, marinos@central.ntua.gr, \\ vmarinos@central.ntua.gr \\ ${ }^{2}$ Attiko Metro S.A., Messogion Str.191-193,115 25,Athens,mnovack@ametro.gr, \\ mbenissi@ametro.gr,kkorkaris@ametro.gr \\ ${ }^{3}$ Engineering Geologist MSc,g_stoumpos@yahoo.co.uk \\ ${ }^{4}$ Hydrogeologist MSc,m_panteliadou@yahoo.gr,d_papouli@yahoo.gr
}

\begin{abstract}
The Thessaloniki Metropolitan Railway comprises two separate $\sim 6 m$ diameter parallel tunnels with an $\sim 8 \mathrm{~km}$ stretch each and 13 stations. The geology of the urban area of Thessaloniki is characterised by the presence of Neogene and Quaternary deposits. The base formation for the project area is a very stiff to hard red clay, dating to Upper Miocene-Pliocene. Upon this formation, Quaternary sediments have been deposited, most of which comprise sand and/or gravel in a clay-silt dominated matrix, covered in places by anthropogenic fill. Ground investigation campaigns incorporated a significant number of sampling boreholes and in situ and laboratory testing. This information was elaborated in order to obtain a better geological understanding and a geotechnical zonation of the ground with respect to mechanised tunnelling. EPBM appears to be the reasonable choice for the project in all aspects of tunnel safety and tunnelling performance. The characteristics and parameters of the soils and the hydrogeological regime directed towards this selection and it is expected that all the objectives, such as settlement and ground movements control, water table level maintenance and adequate performance, will be met by an EPBM provided it is properly operated.
\end{abstract}

Key words: tunnels, TBM, site investigation.

\section{Пврі́̊пчи}

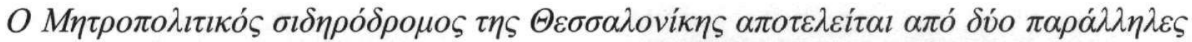

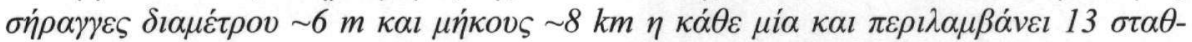

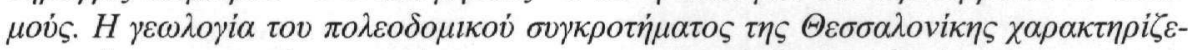

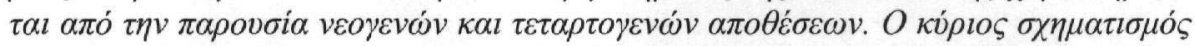

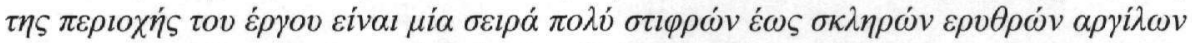

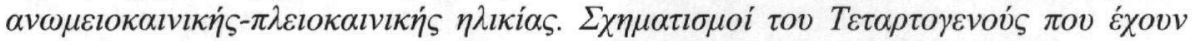

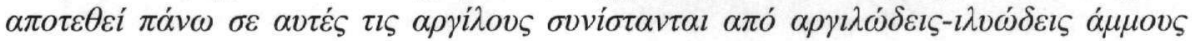




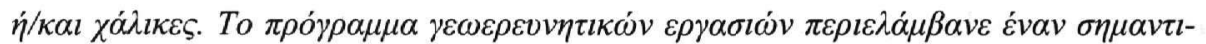

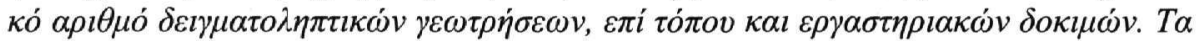

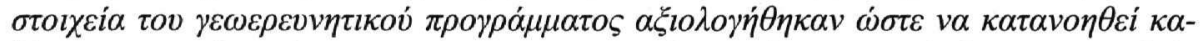

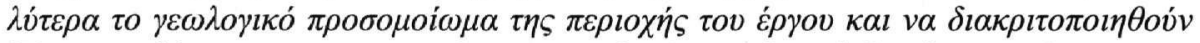

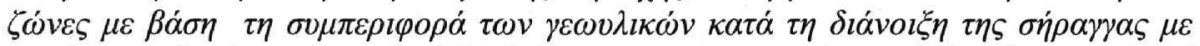

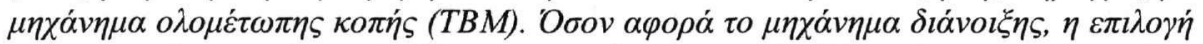

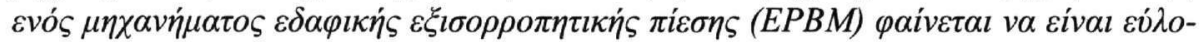

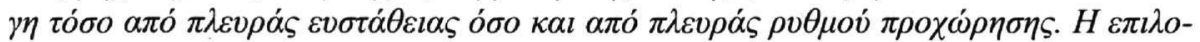

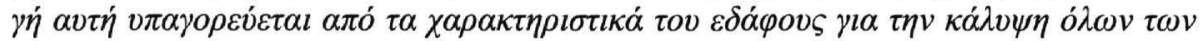

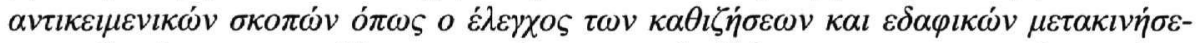

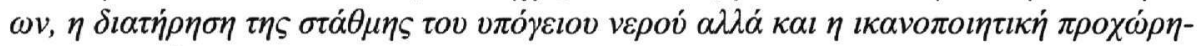
$\sigma \eta \tau \omega v \sigma \eta \rho \dot{\alpha} \gamma \gamma \omega \nu$.

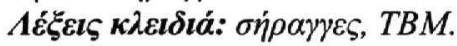

\section{Introduction}

The Thessaloniki Metropolitan Railway (Fig. 1) comprises two separate $\sim 6 \mathrm{~m}$ diameter parallel tunnels with a $\sim 8 \mathrm{~km}$ stretch each and $\sim 1.5 \mathrm{~km}$ of surface rail. The span between the tunnel axes is approximately $12 \mathrm{~m}$ and the depth of the top of rail varies from $15 \mathrm{~m}$ to $30 \mathrm{~m}$. The tunnels will be excavated with the use of two Earth Pressure Balance Machines (EPBM) and the 13 stations either by cover-and-cut (top-down) or by cut-and-cover method.

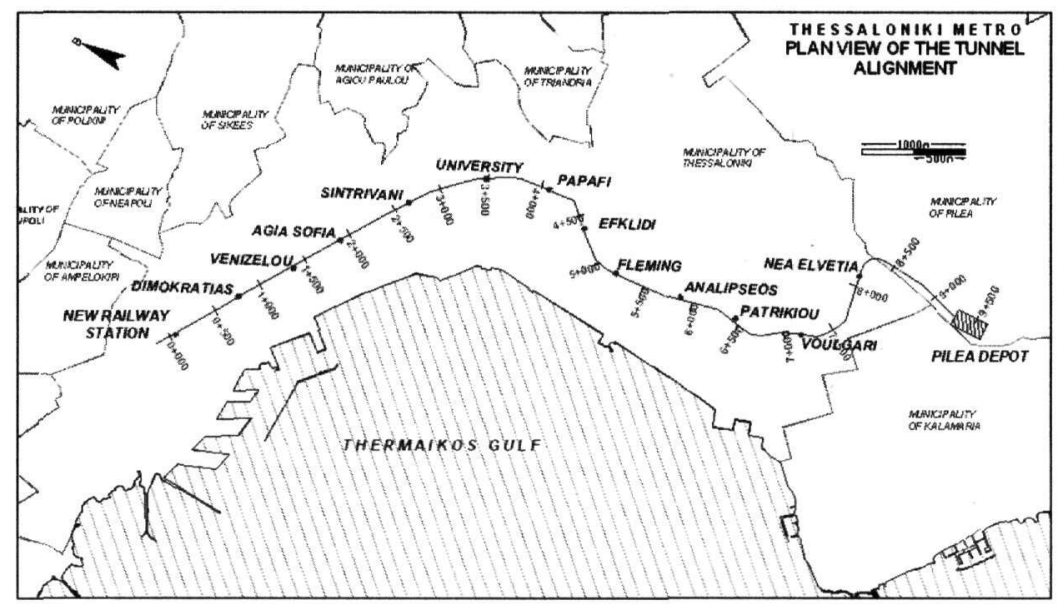

Figure 1 - Plan view of the Thessaloniki Metro

\section{Geology}

The bedrock of the area of Thessaloniki is a Mesozoic gneiss formation that outcrops at the NorthNortheast of the city. This gneiss is overlaid by upper Miocene-lower Pliocene sediments consisting of stiff to hard red clays-silty clays and Quaternary formations of sands, clays, gravels and conglomerates. Due to the long history of the city, an archaeological stratum of significant thickness has been deposited upon these formations, mainly in the city centre area. Gneiss plunges well below the tunnel alignment, probably due to the presence of near-vertical normal faults at the northern area of the city and as such, the base formation in terms of tunnelling works is the red clay stratum. This formation has a significant vertical extent in the project area. 


\section{EPBM operation principles}

The choice of an EPBM for the project was mainly based on the physical characteristics of the ground. The basic operation principle of an EPBM is the support of the excavation face by the excavated material. Figure 2 (from Herrenknecht) illustrates the basic operation procedure during EPBM tunnelling. The soil is excavated by a rotating cutterhead (1) which is fitted with appropriate cutting tools and then enters the working chamber (2). The excavated soil is in a plasticised form having been treated either with water or (where necessary) with conditioning agents thus, an earth paste is produced within the chamber. The pressure in the chamber is controlled and maintained by the combination of: a) the thrust of the EPB which is generated by the thrust cylinders (4) and is transferred in the chamber via the bulkhead (3) and b) the spoil removal rate which is controlled by the rotation speed of the screw conveyor (5) and the advance of the machine. Additionally, the amount of excavated soil that enters the chamber is controlled by the configuration of the cutterhead (which may incorporate moving plates in order to reduce or increase the openings). The presence of the earth paste in the working chamber and the screw conveyor also creates water tight conditions and as such the water table level is not affected by the tunnelling procedure. The final lining of the tunnel is constructed under the protection of the shield and consists of pre-cast concrete segments (7) which interlock creating a solid concrete ring. These are fitted in place by an erector (6).

The appropriate operation of an EPB, which requires the formation of an adequate earth paste in the working chamber, is obviously controlled by the characteristics of the excavated soil. All these characteristics refer to the plasticity, the consistency, the grain size distribution and of the permeability of the ground. Patently, as in any tunnelling technique, the strength of the ground is also of paramount importance. All these parameters were evaluated and the results of this evaluation are discussed in the following paragraphs.

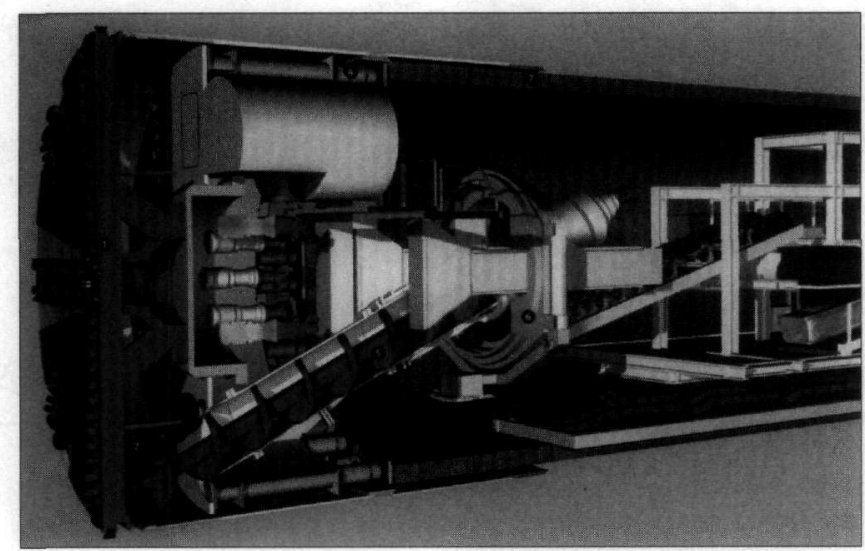

Figure 2 - Typical configuration of an EPBM (from Herrenknecht brochure, note that the selection of the EPB constructor for the Thessaloniki Metro is pending)

\section{Evaluation of ground data}

The data that were evaluated in the present paper were obtained from ground investigation campaigns along the line of the underground railway, dating to 1992,1999 and 2005. These campaigns included 72 sampling boreholes and 52 pressuremeter boreholes.

Statistical analysis of the data was carried out and the results are presented in graphs and in crosssections of the tunnel alignment. These results refer both to the right and left branch of the tunnel, though, for practical reasons, the right branch (south branch) is been projected in the crosssections. 
Analysis of the information and data led to the consideration that the tunnel alignment can be divided in four areas, with respect to the geological and geotechnical conditions that may be encountered during the construction of the tunnel. This geologically based zonation was adopted in order to promote a better understanding of the processed data. These four zones are:

- From chainage $-0+300$ (New Railway Station) to 1+000 (between Dimokratias and Venizelou Station). The area consists of a variety of recent sediments with vertical and lateral transitions

- From chainage 1+000 (between Dimokratias and Venizelou Station) to 4+500 (near Efklidi Station), where stiff and hard clay formations are predominant.

- From chainage 4+500 (near Efklidi Station) to 7+000 (near Voulgari Station). The area comprises a variety of recent sediments with vertical and lateral transitions that extent well below the tunnel invert.

- From chainage 7+000 (near Voulgari Station) to 7+900 (near Nea Elvetia Station) where stiff clay is prevalent

\subsection{Classification tests}

\subsubsection{Particle size analyses -Unified Soil Classification System (U.S.C.S.)}

Classification tests were performed on soil samples obtained from investigating boreholes using sieve and hydrometer analysis. Hydrometer analysis tests correspond to $15 \%$ of the sieve analysis tests (1992 and 1999 campaigns) as they were not performed on all soil samples.

The majority of the tests indicated that, at tunnel depths, the percentage of the samples passing the No 200 sieve $(0.0074 \mathrm{~mm}$, limit between fines and coarse grain size according to the U.S.C.S.) is greater than 40-50\%, denoting that fine-grained materials are dominant along the tunnel alignment (Fig. 3).

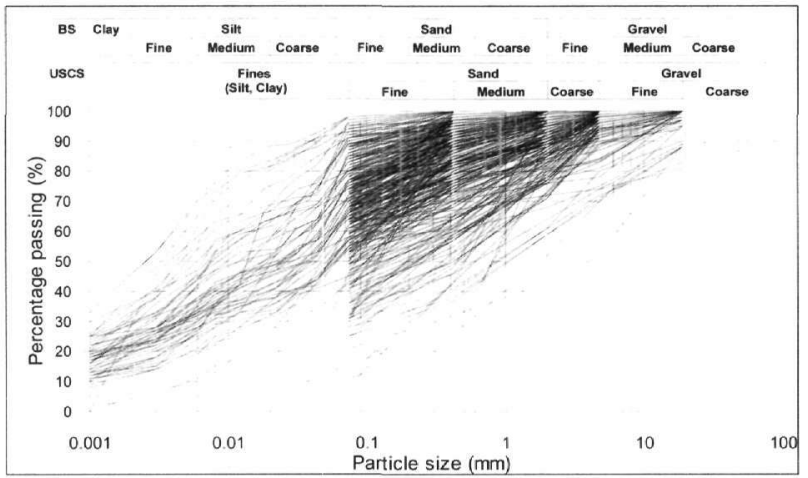

Figure 3 - Grading envelopes of soils within the excavation profile (depth 12 m - 24 m)

Figure 4 presents the spatial distribution graph along the area of the alignment (ch. $-0+300-$ $9+700$ ) showing the soil classification tests according to the U.S.C.S. It is again clear that the fine grain fraction is predominant along the alignment area yet there are restricted areas where deposits with coarser particle size (sand, gravel) and low percentage of fines might be encountered.

\subsubsection{Consistency index}

The consistency index is used to describe the clogging risk during the operation of the machine. It is calculated using liquid limit (LL), plasticity index (PI) and natural moisture content (w \%): 


$$
I_{c}=\frac{L L-w}{L L-P L}=\frac{L L-w}{P I}
$$

Six categories are considered concerning the consistency index of cohesive soils (Bell, 2000): Very stiff to Hard (Ic $\geq 1$, Fig. 5), Stiff $(1<\mathrm{I} c \leq 0.75)$, Firm $(0.75<\mathrm{I} \leq \leq 0.50)$, Soft $(0.50<\mathrm{I} \leq \leq 0.25$, Fig. 6 ), Very soft $(0.25<\mathrm{Ic} \leq 0.00)$ and Liquid $(\mathrm{Ic}<0.00)$. Stiff and very stiff to hard conditions are predominant in the overburden and at tunnel depths along the alignment. However in the area between chainages $5+800$ and $6+800$, samples of lower consistency were indicated. Figure 5 shows the distribution of consistency index along the area of the tunnel alignment for all samples.

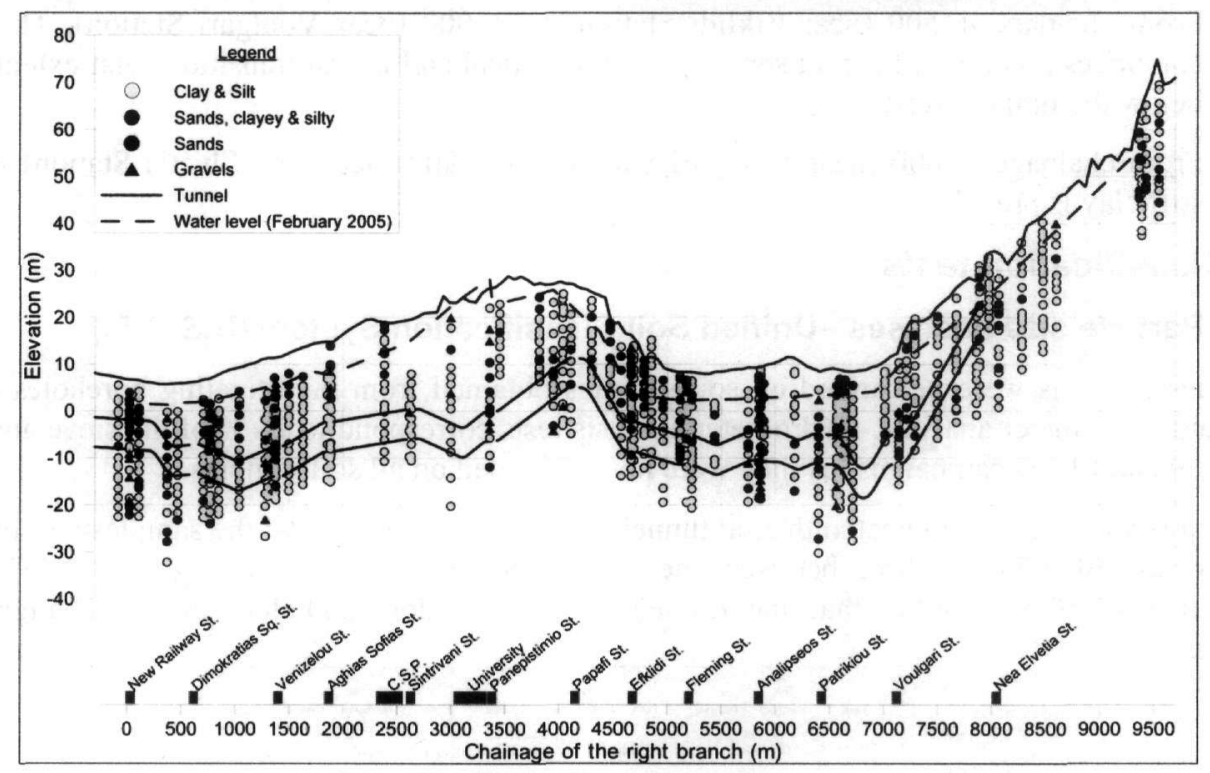

Figure 4 - Distribution of soil type classified according to the U.S.C.S along the alignment

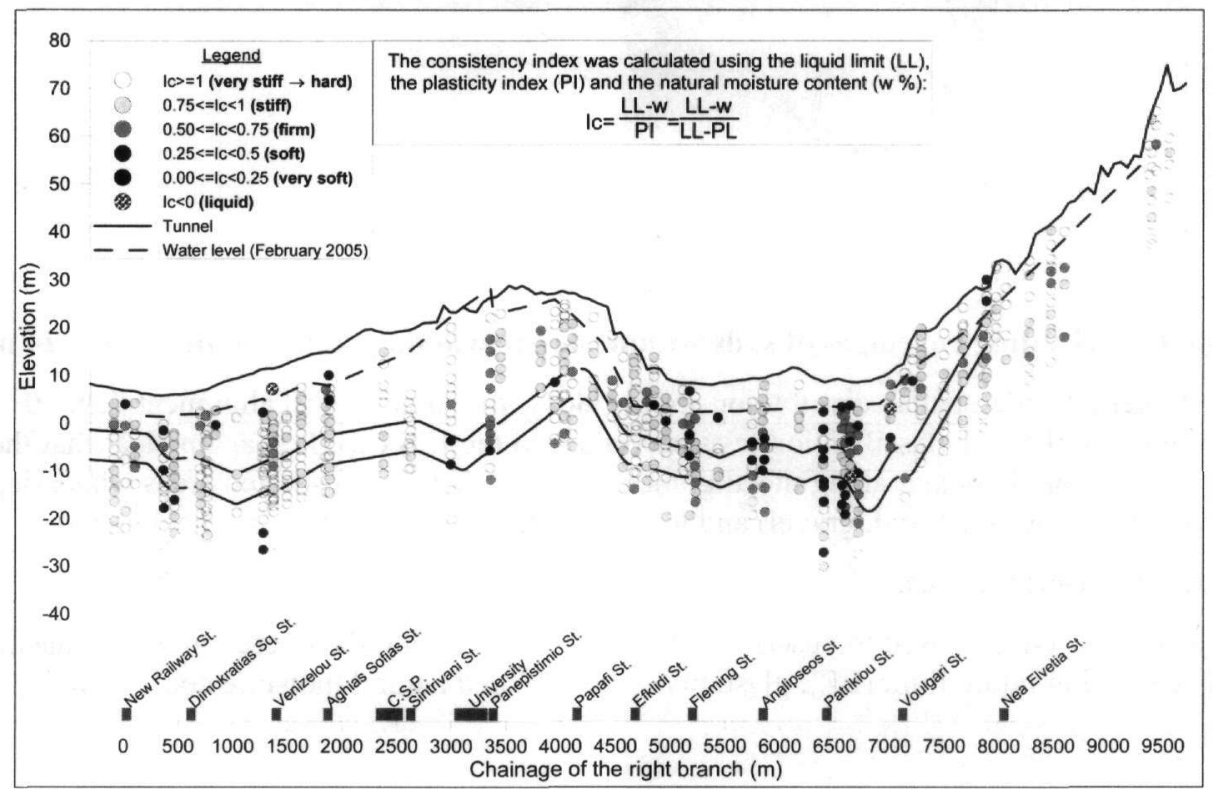

Figure 5 - Consistency index distribution graph along the area of the alignment 


\section{2. 'Sticky behaviour' of cohesive soils}

Some types of cohesive soils, especially those consisting of highly plastic clays, have the tendency to develop sticky behaviour (adhesion of clay particles to metal surfaces and/or cohesion of clay particles, sticking to each other) that may lead to clogging in the cutterhead, working chamber, and screw conveyor of an EPBM or obstruct the shield advance due to friction. In this section, potential clogging risks during the Thessaloniki Metro construction are discussed with respect to criteria mentioned in various papers.

Geodata-Torino (1995) studied the sticky behaviour of cohesive materials for the Athens Metro Line 3 Extension and proposed the criteria and conditions shown in figure 6. This graph shows the relationship between the ratio of natural moisture content to plastic limit, the plasticity index and the categories for clogging risk. The data points suggest that the cohesive soils to be encountered in Thessaloniki Metro have low to medium tendency to 'sticky behaviour'.

A similar approach on the matter was introduced by Thewes et al. (2004). The authors studied the geological information from tunnel drives where problems of different scale occurred due to clogging and proposed three categories of clogging potential. The graph in figure 7 shows the relationship between the consistency and plasticity indices and the categories for clogging potential. As the authors notice, the graph provides an indication of clogging risks for fluid supported shield drives. This approach is less optimistic than the Geodata-Torino assessment.

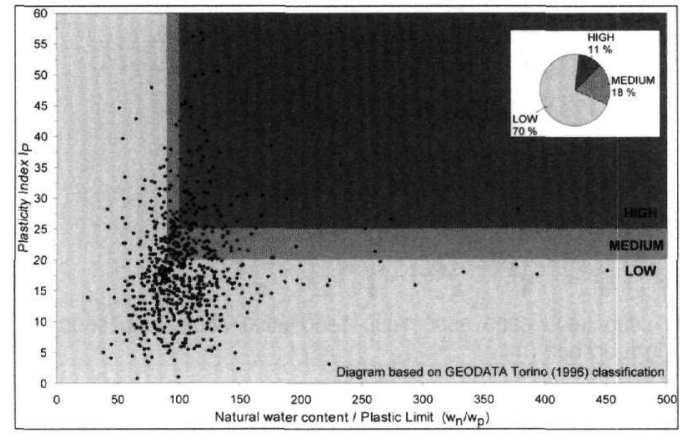

Figure 6 - 'Sticky behaviour' of cohesive soils of Thessaloniki Metro area (based on the Geodata-Torino, 1995 classification)

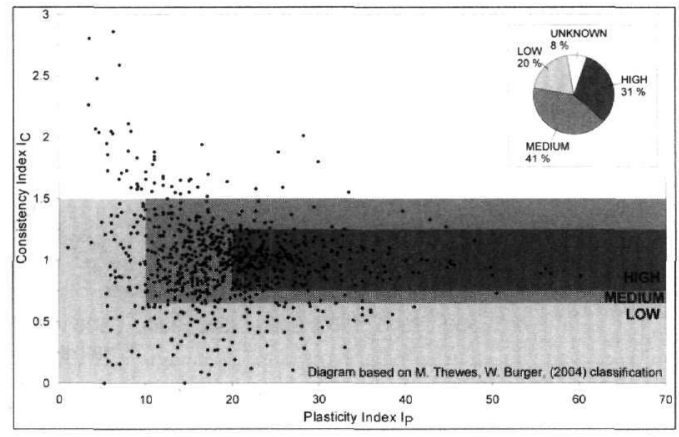

Figure 7 - 'Clogging risk' of cohesive soils of Thessaloniki Metro area (based on Thewes et al. 2004 classification)

\subsection{Standard Penetration Tests (SPT)}

Standard Penetration Tests (SPT) were executed in most boreholes. The majority of the measurements $(\sim 60 \%)$ indicated refusal during the tests, whilst approximately $15 \%$ of the values demonstrated a $N_{\text {SPT }}$ value less than 15 . However, it can be said that the latter values are mainly restricted to a depth down to $15 \mathrm{~m}$, i.e. mainly in the overburden.

The results of the SPT were divided in four classes: $\mathrm{N} \leq 8, \mathrm{~N} \leq 15,15<\mathrm{N} \leq 30,30<\mathrm{N} \leq 50$ and refusal (Fig. 8). It can be noticed that:

- In the area between ch. $-0+300$ and $1+000, \mathrm{~N}_{\mathrm{SPT}}$ values less than 15 were recorded mainly in the overburden yet few values between 15 and 30 also occurred at lower depths.

- In the area between ch. $1+000$ and $4+500$, the available data were limited or even absent as far as it concerned the area of the tunnel face due to the lowering of the initial tunnel alignment in order to avoid the archaeological stratum. This 'gap' was filled with the execution of TP1103 and TP1104 during the 2005 campaign. The evaluation of these data suggests that the ground conditions are favourable at tunnel depths. 
- In the area between ch. $4+500$ and $7+000$, the occurrence of very low and low $\mathrm{N}_{\mathrm{SPT}}$ values is more intense mainly in the overburden. With respect to the excavation profile, $\mathrm{N}_{\mathrm{SPT}}$ values are generally greater than 15 , although high $\mathrm{N}_{\mathrm{SPT}}$ values and refusals are almost absent. These strata of lower $\mathrm{N}_{\mathrm{SPT}}$ values appear to form a 'valley' within the more competent formations, stretching from ch. $4+500$ to $7+000$.

- In the area between ch. $7+000$ and $7+900$, the tests indicated $N_{S P T}$ values much greater than 15 in the overburden. At tunnel depths the available data are limited.

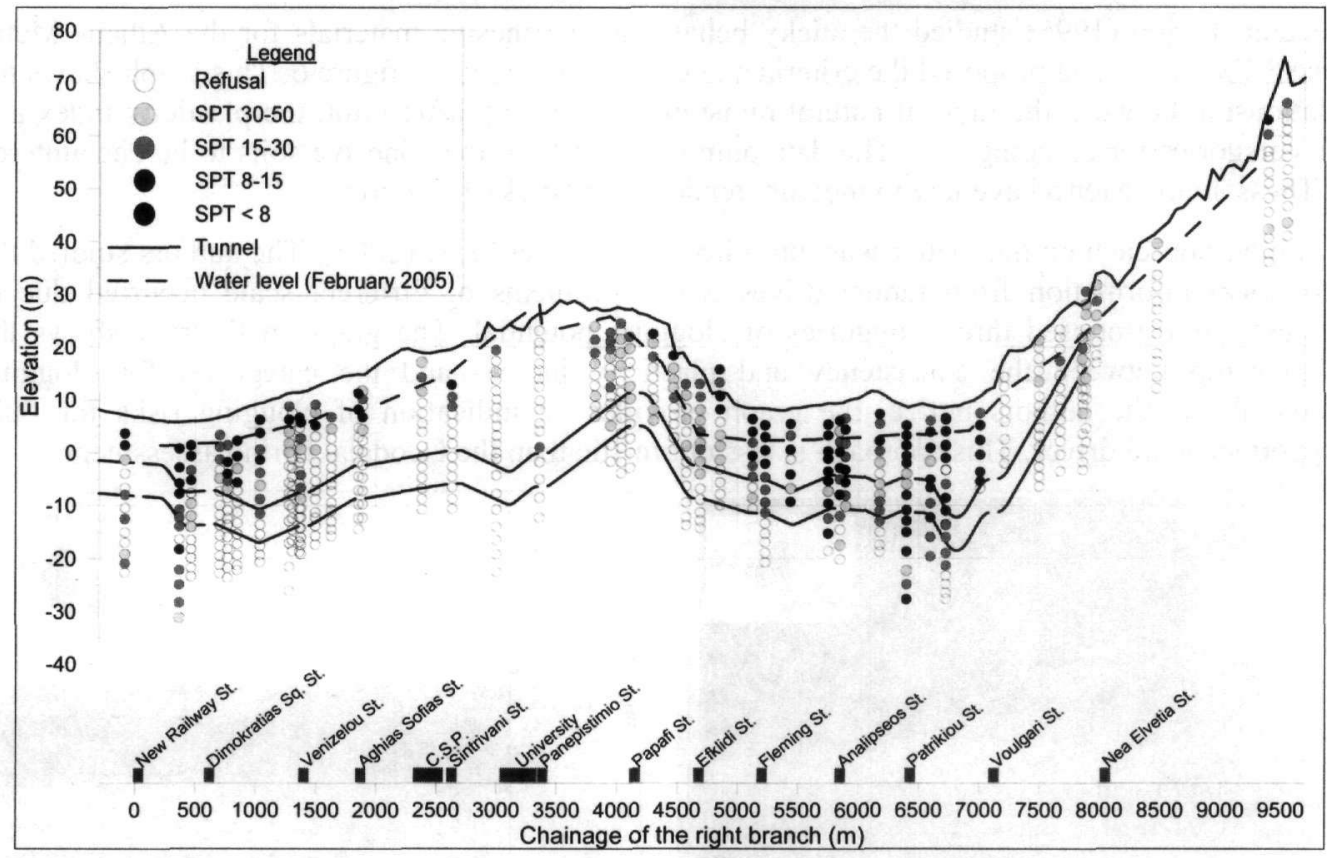

Figure $8-\mathbf{N}_{\text {SPT }}$ value distribution graph along the area of the alignment

These conclusions promote the initial assumption on the existence of four zones with different expected geological and/or geotechnical conditions. Extremely low values of less than 8 are localised in the upper strata between chainages $0+450$ and $1+800$ where they can be attributed to the presence of the archaeological stratum and in the area between chainages $5+000$ and $7+000$, an area within the previously indicated zone of low $\mathrm{N}_{\mathrm{SPT}}$ values.

Another useful conclusion from the assessment of $\mathrm{N}_{\mathrm{SPT}}$ values is their correlation with the undrained shear strength $(\mathrm{Cu})$ of the tested soil. This correlation, based on the following table and on the equation: $\mathrm{q}_{\mathrm{u}}=2 \mathrm{Cu}$, was used to obtain a $\mathrm{Cu}$ distribution graph along the area of the alignment, $\mathrm{q}_{\mathrm{u}}$ being the unconfined compressive strength. This correlation was used to provide a wider view of the geotechnical conditions of the area, in conjunction with the corresponding pressuremeter-Cu correlation (Fig. 10).

Table 1 - Relation of soil consistency, number of blows and unconfined compressive strength (Terzaghi et al. 1996)

\begin{tabular}{|c|c|c|c|c|c|c|}
\hline $\mathbf{N}_{\text {SPT }}$ & $<2$ & $2-4$ & $4-8$ & $8-15$ & $15-30$ & $>30$ \\
\hline Soil consistency & Very soft & Soft & Medium & Stiff & Very stiff & Hard \\
\hline $\mathbf{q}_{\mathbf{u}} \mathbf{( k P a )}$ & $<25$ & $25-50$ & $50-100$ & $100-200$ & $200-400$ & $>400$ \\
\hline
\end{tabular}




\subsection{Pressuremeter Tests}

The 1999 investigation campaign incorporated pressuremeter tests which were undertaken in 52 boreholes $(\varnothing 60 \mathrm{~mm})$ drilled for this reason. These boreholes were interspersed along the whole alignment, they were rotary cored and logging of the cores was also conducted. The tests were executed using either a $\emptyset 60 \mathrm{~mm}$ or a $\emptyset 44 \mathrm{~mm}$ Menard type probe at $1.5 \mathrm{~m}$ intervals.

\subsubsection{Undrained shear strength}

The recorded raw data were used to estimate the undrained shear strength of each tested soil, using the limit pressure method equation:

\section{Equation 2 - Limit pressure method equation, Briaud, 1992}

$$
\mathrm{p}_{1}-\mathrm{p}_{\mathrm{o}}=\left[\ln \left(\frac{\mathrm{G}}{\mathrm{Cu}}\right)+1\right] \mathrm{Cu}
$$

where $\mathrm{p}_{1}$ is the recorded limit pressure in $\mathrm{kPa}, \mathrm{p}_{\mathrm{o}}$ the horizontal field stress in $\mathrm{kPa}, \mathrm{G}$ the shear modulus in $\mathrm{kPa}$ and $\mathrm{Cu}$ the undrained shear strength in $\mathrm{kPa}$. This approach does not require any assumption for the Poisson's ratio (v) value and as such, it is considered to be more reliable.

Figure 9 presents the calculated $\mathrm{Cu}$ values along the alignment providing a two-dimensional image of the expected geotechnical regime in the project area. As can be seen, the estimated $\mathrm{Cu}$ values were divided in 6 categories with the values of $\mathrm{Cu}$ greater than $400 \mathrm{kPa}$ to be the most abundant, denoting the increased presence of competent strata along the profile.

The lower values of $\mathrm{Cu}$ that occur at shallow depths can be attributed to the fill material and the archaeological stratum. However, there are areas where low values of $\mathrm{Cu}$ occur at depths where they cannot be correlated with either man-made deposits or the weathering mantle. These areas are delineated between ch. $0-300$ to $1+000$ and $4+500$ to $7+000$. The latter concurs with the conclusions extracted from the $\mathrm{N}_{\mathrm{SPT}}$ distribution graph. The presence of less competent formations at these depths may indicate a differentiation on the soil lithology. However, the vast majority of the pressuremeter tests, at depths below the fill material and the weathering mantle, suggest that the ground concerning immediately the project area consists of high shear strength soil formations.

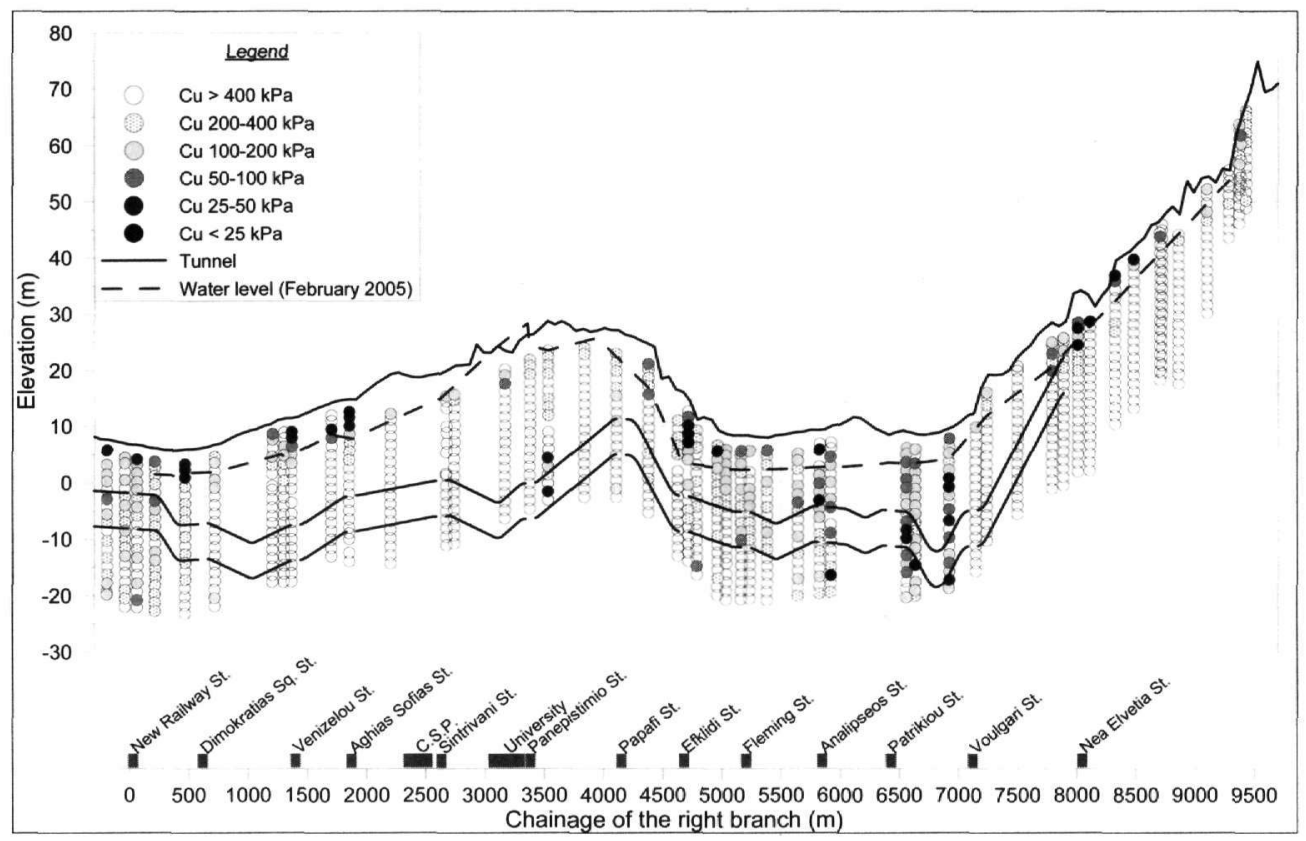




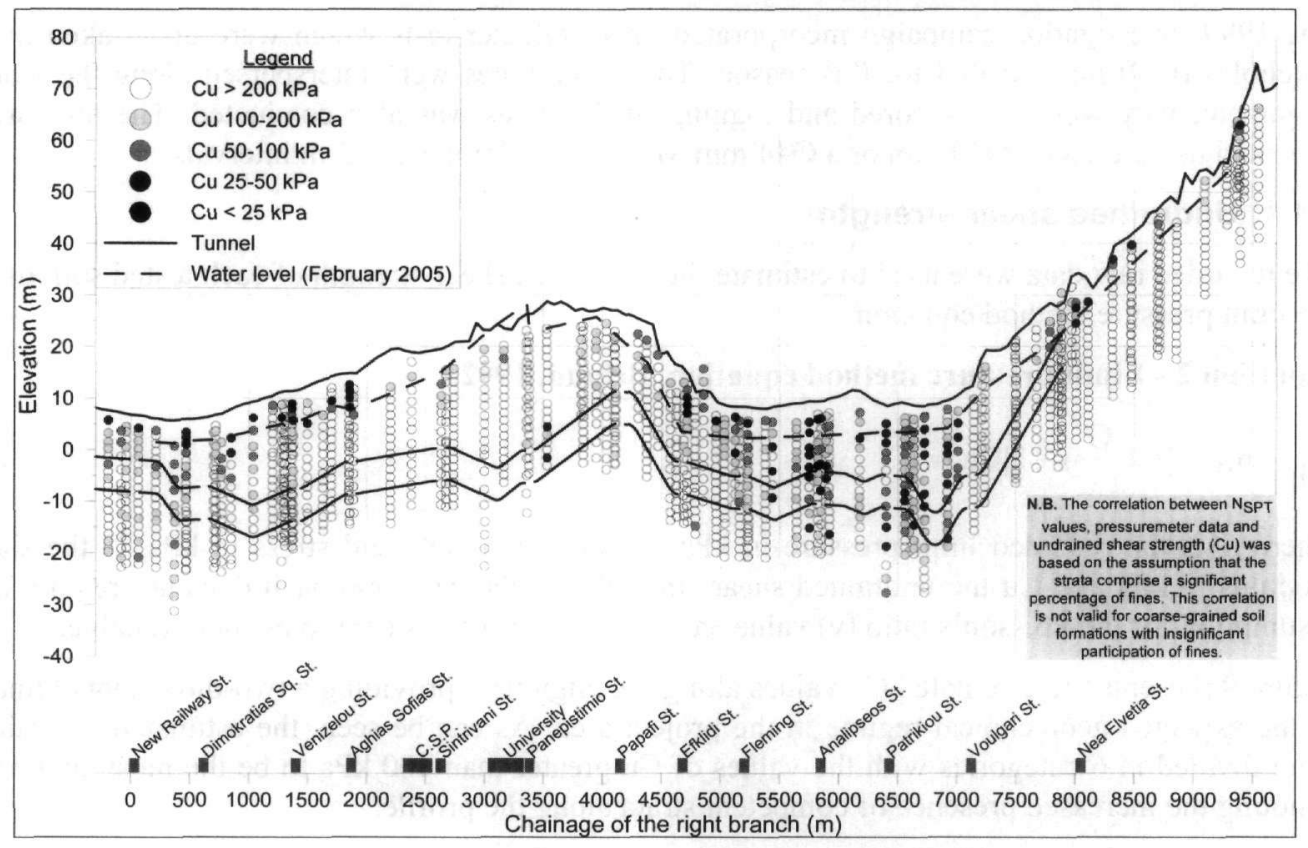

Figure 10 - Undrained shear strength values as calculated from SPT and pressuremeter tests

\subsubsection{Ground model}

Apart from testing, the pressuremeter boreholes incorporated core logging. Based on these descriptions and in conjunction with Table 2 (AFNOR specifications, 1993 from Kavvadas 2005) and the limit pressure test values a ground model was produced.

Table 2 - Soil type - limit pressure correlation (AFNOR, 1993 from Kavvadas, 2005)

\begin{tabular}{|c|c|c|c|c|c|c|}
\hline \multirow{2}{*}{ Soil type } & \multicolumn{3}{|c|}{ Clay-Silt } & \multicolumn{3}{c|}{ Sand-Gravel } \\
\cline { 2 - 7 } & Soft & Stiff & Hard & Loose & Medium & Dense \\
\hline Limit pressure (p, MPa) & $<0.7$ & $1.2-2$ & $>2.5$ & $<0.5$ & $1-2$ & $>2.5$ \\
\hline
\end{tabular}

The primary classification (fine grained or coarse grained) was based on the core description whereas the secondary classification (density and consistency) on the pressuremeter test data. Two areas exhibit increased presence of coarse-grained material and/or low density fine-grained material. This fact confirms the conclusions extracted from the undrained shear strength approach as these two areas are included in the already distinguished zones.

\subsection{Evaluation of in situ permeability tests}

Overall, 214 falling head, 13 constant head and 12 packer in situ permeability tests were undertaken in the project area. The prevalence of falling head tests over constant head is characteristic of the persistence of low permeability soils for which this type of testing is more appropriate.

Permeability values extend from $5 \cdot 10^{-5} \mathrm{~m} / \mathrm{sec}$ to lower values, with the majority of the measurements ranging between $10^{-6} \mathrm{~m} / \mathrm{sec}$ and $10^{-8} \mathrm{~m} / \mathrm{sec}$. At greater depths, the values of hydraulic conductivity are lower $\left(1 \cdot 10^{-8}\right.$ to $\left.5 \cdot 10^{-7} \mathrm{~m} / \mathrm{sec}\right)$. 




Figure 11 - Permeability (hydraulic conductivity) distribution graph along the area of the alignment, based on in situ permeability tests

Higher values $\left(\mathrm{k} \geq 1 \cdot 10^{-5} \mathrm{~m} / \mathrm{sec}\right)$ were recorded in the area between the ch. $0+500$ and $2+000$, as well as in the area between the ch. $4+700$ and 5+200 (Fig. 11). It should be noted that the results of the in situ permeability tests should be adopted with prudence since sometimes they are biased towards lower values of permeability. Moreover, indications of the presence of past or active torrent river beds should also be taken into consideration as water bearing formations might be encountered, although restricted in width. The indicative position of present streams is also shown in figure 11 .

\section{TBM selection justification}

From the early stages of the project it was decided that tunneling works for the Thessaloniki Metro would be undertaken with the use of TBMs rather than conventional excavation methods. This decision was mainly based on environmental and schedule issues since TBM tunnelling requires fewer surface installations and provides a much higher advance rate. The nature of the geological formations of the area and the vicinity of the tunnel with large and/or sensitive surface structures (i.e. ancient buildings and buildings already affected from the seismic events that have influenced the city) suggested that any TBM used for the project would have to utilise a face support system in order to minimise the settlements induced at the surface. The selection of an EPBM rather than a different type of closed face TBM (compressed air, slurry TBM, mixshield) is justified by all findings of the ground investigation campaigns.

The primary and probably most important aspect in the TBM selection process is the grain size distribution of the soils that will be encountered during tunnelling. Figure 16 shows the average grading envelope of 429 tests along the tunnel alignment.

These tests are those that correspond to samples taken from boreholes at depths between 12 and 24 $\mathrm{m}$, a range which is the depth within which the tunnel will be excavated. These envelopes were examined in terms of suitability for each type of TBM using various references from acknowledged sources. The one shown in figure 12 is from L.Langmaack (2002). Similar conclusions were extracted from other relevant graphs. 
The average grading envelope clearly suggests that the soils to be encountered during tunnelling comprise high percentage of fines; a fact that justifies the selection of an EPBM. British Tunneling Society and the Institution of Civil Engineers in a recent publication (Anonymous 2005) suggest that the percentage of fines should be higher than 10\% for an EPBM to work properly. It is apparent from figure 12 that an EPBM should be able to effortlessly confront the soils of the project area.

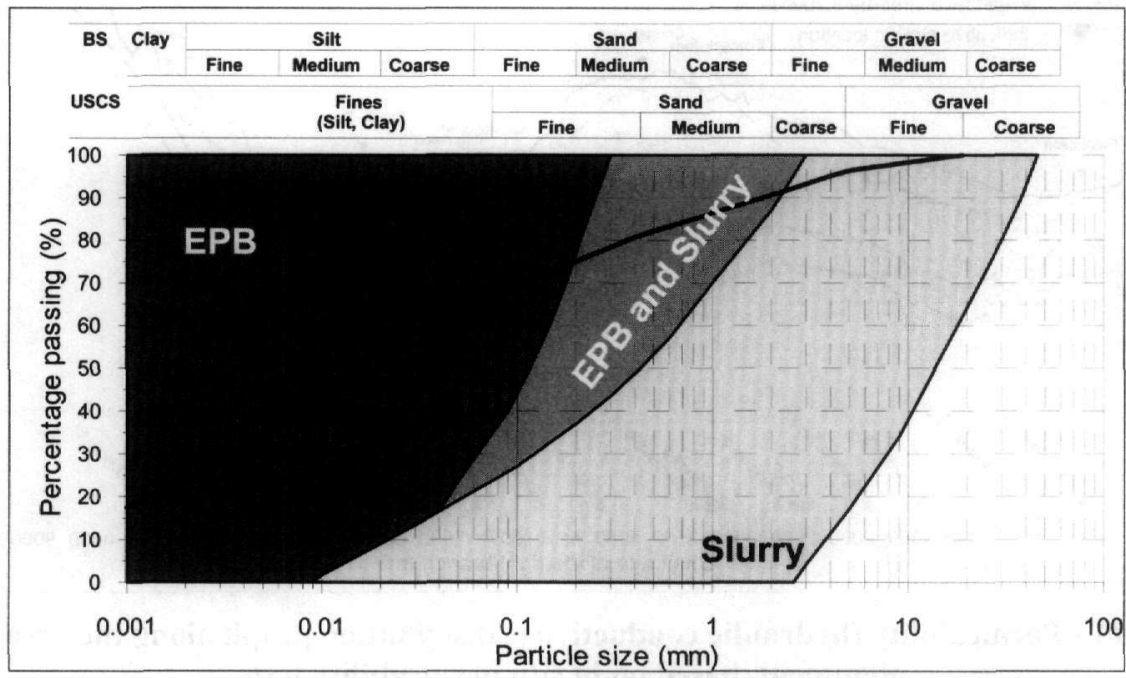

Figure 12 - Average grading envelope of the excavation profile soils in Thessaloniki ground (bold line) and EPB and Slurry suitability limits (suitability limits from Langmaack 2002)

In general, where the excavated soil does not have the characteristics that would assure the forming of an adequate earth paste, conditioning agents are added so as to treat the spoil and provide the necessary parameters to maintain the appropriate face support and spoil characteristics. These agents may be water (where the natural moisture content of the soil is not sufficient), foam or polymers. In the soils of Thessaloniki, the choice of the appropriate conditioning will not be a problem given the clayey characteristics of the ground.

The potential presence of coarser material or even boulders is not expected to create severe problems to the boring procedure since, in most cases, this coarse material is embraced by a clayeysilty matrix which aids the formation of an adequate earth paste in the EPBM's working chamber while keeping the use of conditioning agents at reasonable levels.

In terms of permeability, BTS and ICE (2005) indicate as "the point of selection" between EPBMs and Slurry TBMs a ground permeability of $1 \times 10^{-5} \mathrm{~m} / \mathrm{s}$ with the Slurry TBMs being more suitable for higher values and accordingly EPBMs for lower. The in-situ permeability tests were elaborated and approximately $95 \%$ of them indicated permeability values lower than $1 \times 10^{-5} \mathrm{~m} / \mathrm{s}$. Thus, an EPBM is more suitable for the largest part of the alignment with the need for increased use of conditioning agents reduced to just a few isolated sections of the TBM route.

In general, an EPBM appears to be the reasonable choice for the project in all aspects of tunnel safety and tunnelling performance. The characteristics and parameters of the soils and the hydrogeological regime direct towards this selection and it is expected that all the objectives, such as settlement and ground movements control, water table level maintenance and adequate performance, will be met by an EPBM provided it is properly operated. 


\section{Conclusions}

The present paper clearly shows how the treatment and assessment of the results of the in-situ and laboratory testing supported a geologically based zonation in the soils that cover all the area of the drive. Two zones with less competent formations, each followed by an area of relatively favourable geotechnical conditions, are expected to be encountered during the Thessaloniki Metro construction.

These weak zones are distinguished by clear differences in all geotechnical aspects such as the $\mathrm{N}_{\mathrm{SPT}}$ values, the undrained shear strength, the variability of the material as derived from the soil classification according to the A.U.S.C.S. and also differences in the nature and the consistency of the comprising soils. The more competent zones are generally formed by hard to stiff clays of ample geotechnical behaviour.

The geotechnical characteristics and parameters, in conjunction with the low permeability, justified the selection of EPBMs. EPBMs are expected to perform efficiently with low rate conditioning in the largest part of the alignment. Settlements and ground movements can be sufficiently controlled.

\section{Acknowledgments}

We would like to thank Attiko Metro S.A. for their support and permission to publish this paper.

\section{References}

Anonymous, 2005. Closed-face tunnelling machines and ground stability, British Tunnelling Society (Closed-Face Working Group) in association with the Institution of Civil Engineers, Thomas Telford Publishing, London, 77pp.

Bell, F.G., 2000. Engineering properties of soils and rocks, Blackwell Science Ltd, Oxford, 482 pp.

Geodata S.p.A., 1995. Report: Review of alternative construction methods and feasibility of proposed methods for constructing Attiko Metro Extension of Line 3 to Egaleo, Attiko Metro S.A., 191-193, Messogion Ave., 11525 Athens, Greece.

Herrenknecht, AG, unknown. Pioneering tunnelling technology for underground transport systems. (Brochure).

Kavvadas, M.J., 2005. Personal communication-material for the lectures of the module 'Foundations', National technical University of Athens, Iroon Politechniou 9, 15780 Zografou, Greece. (in Greek)

Langmaack, L., 2002. Soil conditioning for TBM-Chances and limits: Journées d'études internationales de Toulouse-Underground works: Living structures, AFTES.

Terzaghi, K., Peck, R.B., and Mesri G., 1996. Soil mechanics in engineering practice, John Wiley \& Sons INC, New York, NY, 549pp.

Thewes, M., and Burger W., 2004. Clogging risks for TBM drives in clay, Tunnels \& Tunnelling International, June 2004, 28-31. 